\title{
estructuras laminares en España
}

\author{
arquitecto: FRAY COELLO DE PORTUGAL
}

$886-18$

\section{sinmposis}

Se exponen aquí tres interesantes cubiertas laminares para respectivas iglesias situadas en diferentes puntos de la geografia hispana.

Se han de resaltar sus magníficos resultados y comportamiento, así como la gran espectacularidad conseguida y su bajo costo relativo, sobre todo a la vista de la plasticidad formal y el dramatismo estructural de las soluciones adoptadas. El arquitecto Fray Coello de Portugal aportó las ideas generales de diseño, encargándose el proyecto, supervisión, cálculo, planos, detalles,

Este trabajo fue presentado en la IASS-1967 de México.

\section{iglesia en Tormelavega}

PROPIETARIAS:

Reverendas Madres de los Sa grados Corazones.

ARQUITECTOS ESTRUCTURA. LES :

José Ruiz-Castillo.

Ricardo Urgoiti.

Ignacio Faure $(\dagger)$.

El arquitecto proyectó una bóveda cuadrada en plan ta, apoyada en dos vértices bajos opuestos y con los vértices altos a distinto nivel, cubriendo un área de $23 \times 23 \mathrm{~m}$. Esta asimetría complicaba la forma de los complicaba la forma de lo contrafuertes, los cuales debían tomar el empuje de la cubierta en $3 \mathrm{~m}$ de al tura.

La bóveda laminar se calculó para peso de aislamien to y nieve. Se liberaron de esfuerzos normales los dos bordes más inclinados, pudiendo éstos rematarse con un miembro muy reducido dadas las proporciones de dadas las proporciones de la estructura. Los bordes menos inclinados constan de una viga alabeada más resistente, con un armado mayor. Unos montantes tubulares en el plano vertical del ventanal sirven para soportar el peso propio de esta viga $y$, a la vez, canalizar la flexión en su plano de mayor inercia.

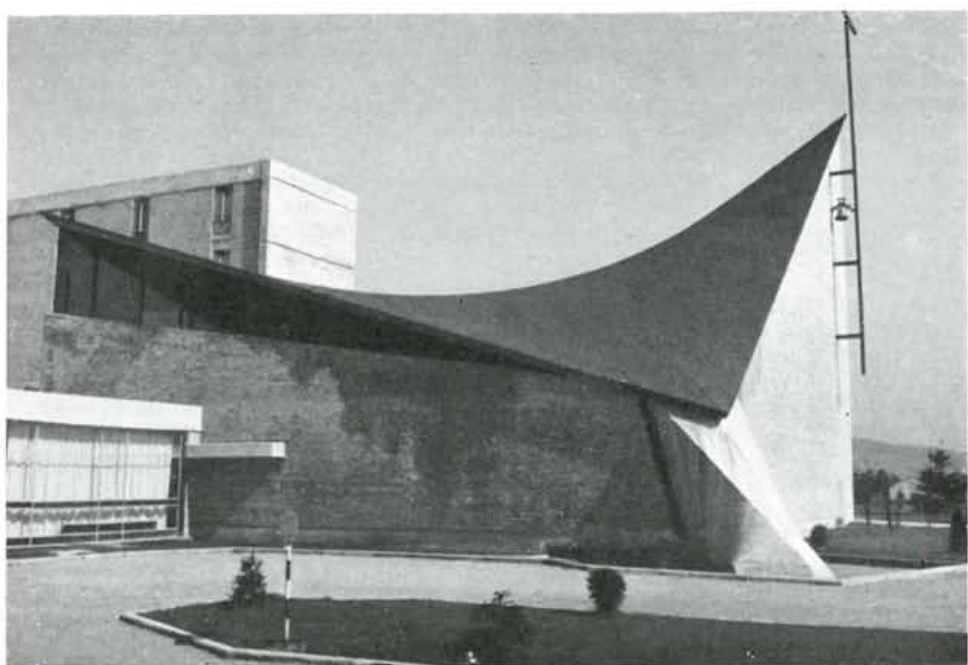

Vista lateral. Aspecto de uno de los apoyos.

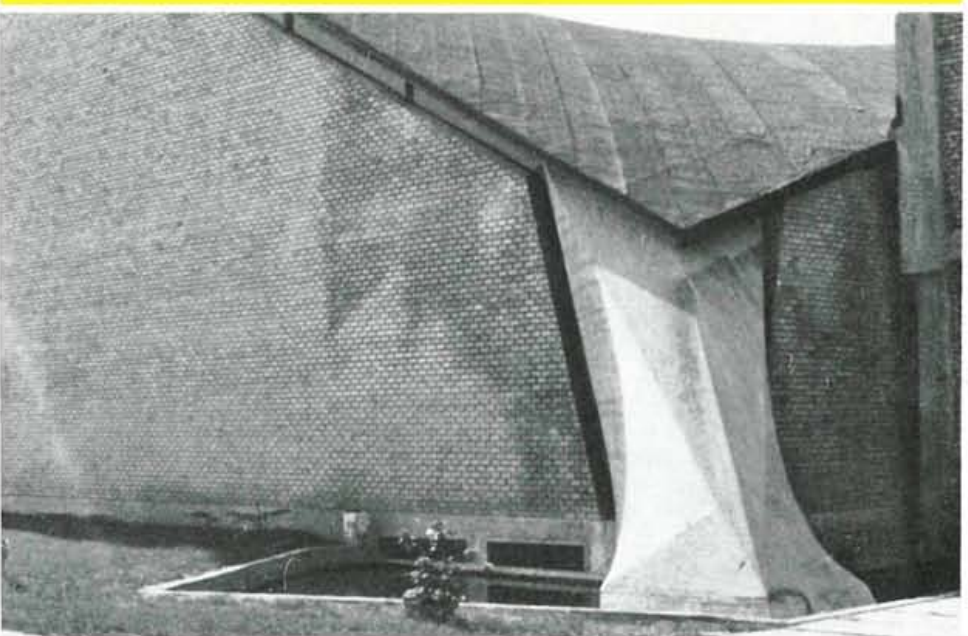




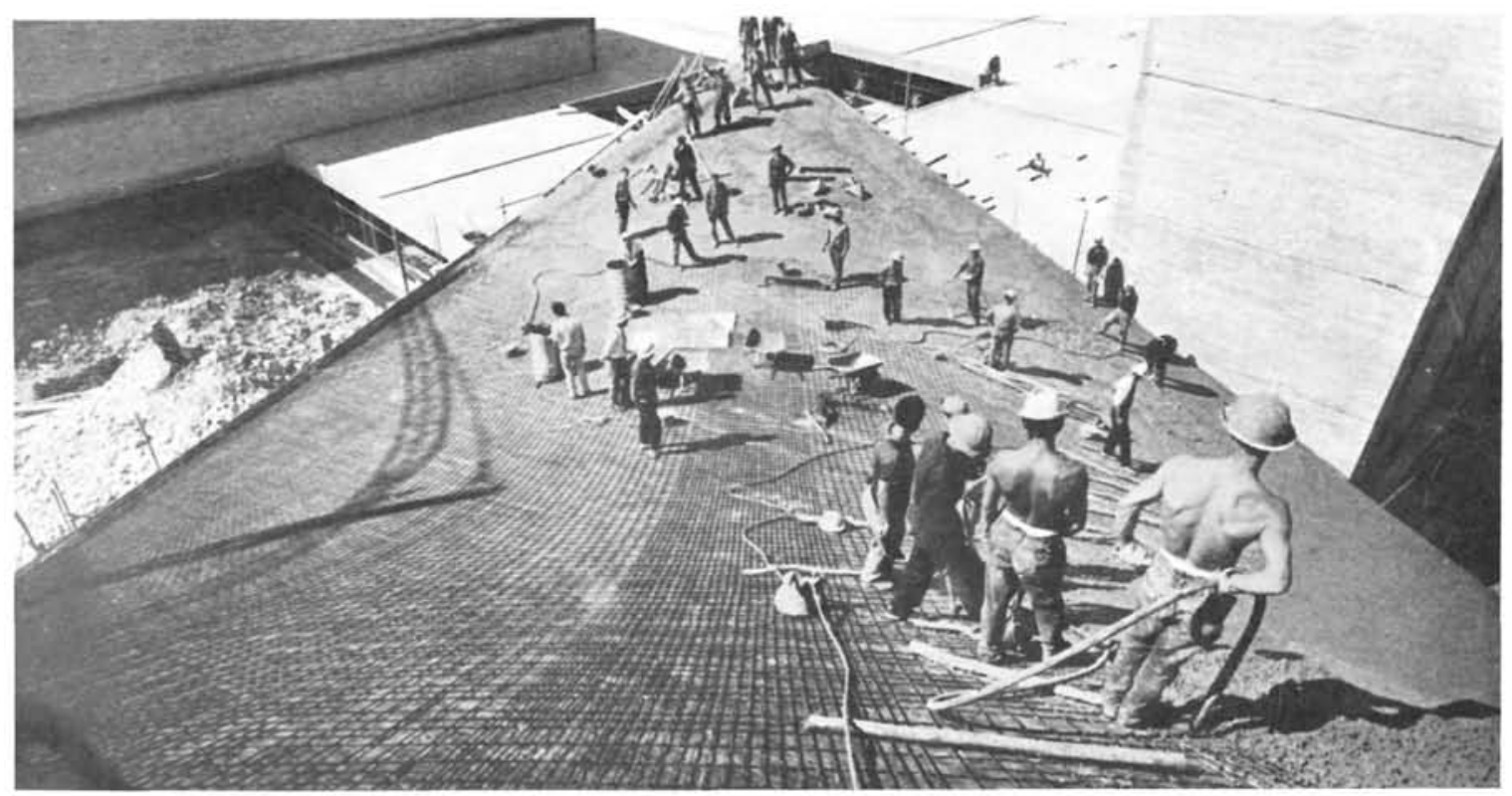

Vista del hormigonado de la cubierta.

Los contrafuertes son muy robustos y descansan en una zapata muy ancha, para evitar al máximo el giro en la dirección del empuje, que podría resultar peligroso para la lámina, ya que el tirante se encuentra enterrado por debajo del pavimento. Una cierta holgura en el presupuesto permitió, en este caso, dotar a estos elementos de forma adecuada, con un criterio escultórico. El tirante fue tensado desde atrás de los contrafuertes, para evitar deformaciones.

La peculiaridad que ofrece la estructura es la gran sensación de ligereza que proporciona por la esbeltez de los nervios de borde, los cuales se encuentran disimulados aprovechando el efecto óptico que desde el exterior se consigue al imaginar la continuidad de la cara baja de la visera con la lámina.

La construcción de la estructura fue impecable, hormigonándose en una sola jornada, y consiguiéndose una resistencia característica del hormigón superior a $300 \mathrm{~kg} / \mathrm{cm}^{2}$. Al desencofrar no se pudo observar la menor grieta ni incremento alguno en la separación de los arranques.

Los muros de cerramiento se han levantado muy altos, dejando hasta la lámina unas rendijas, de manera que desde el interior prevalece la impresion de que ésta se encuentra libre y separada por completo de aquéllos. Debajo de la iglesia existe un salón de actos de las mismas dimensiones.

Aspecto exterior.

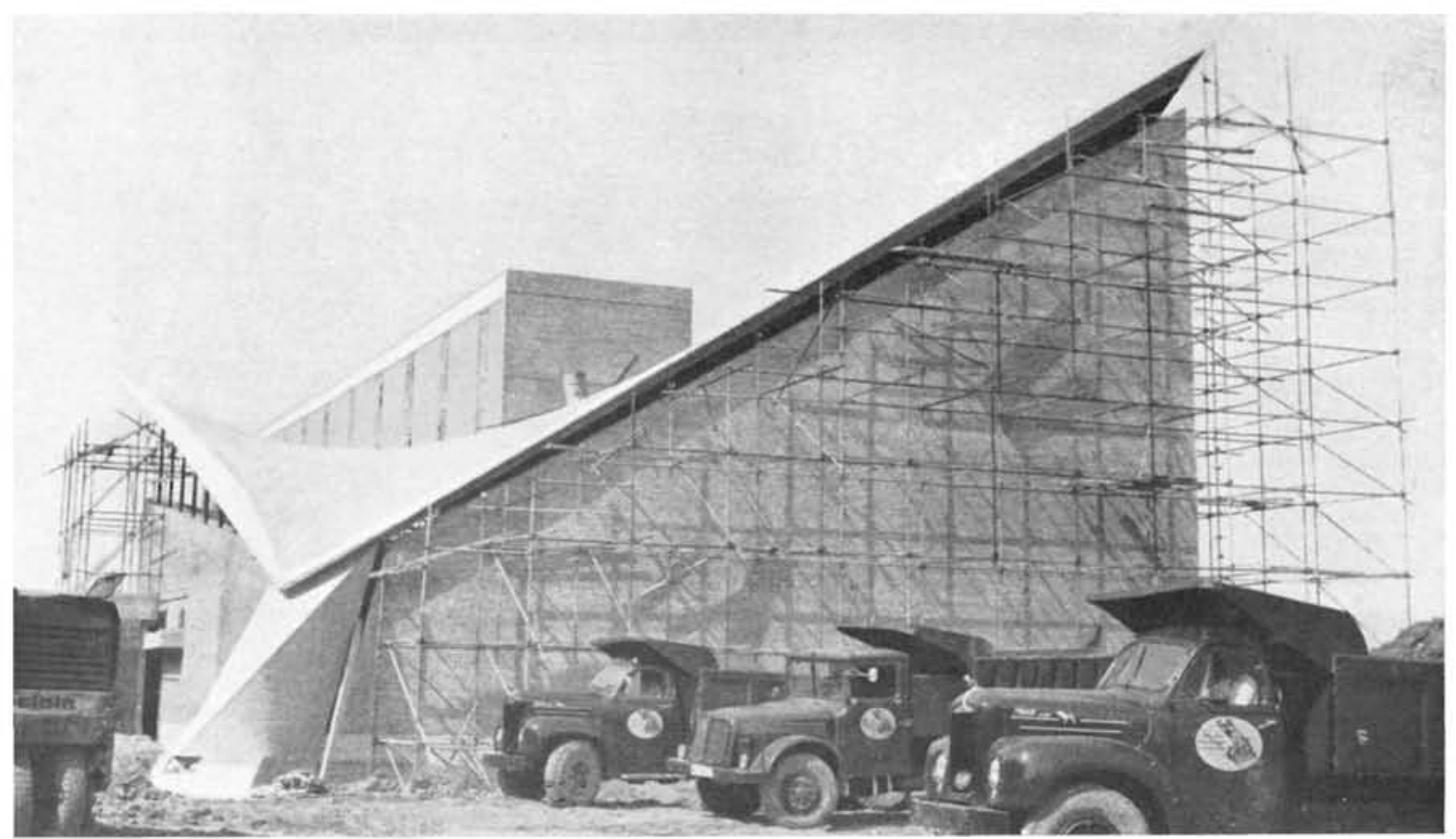



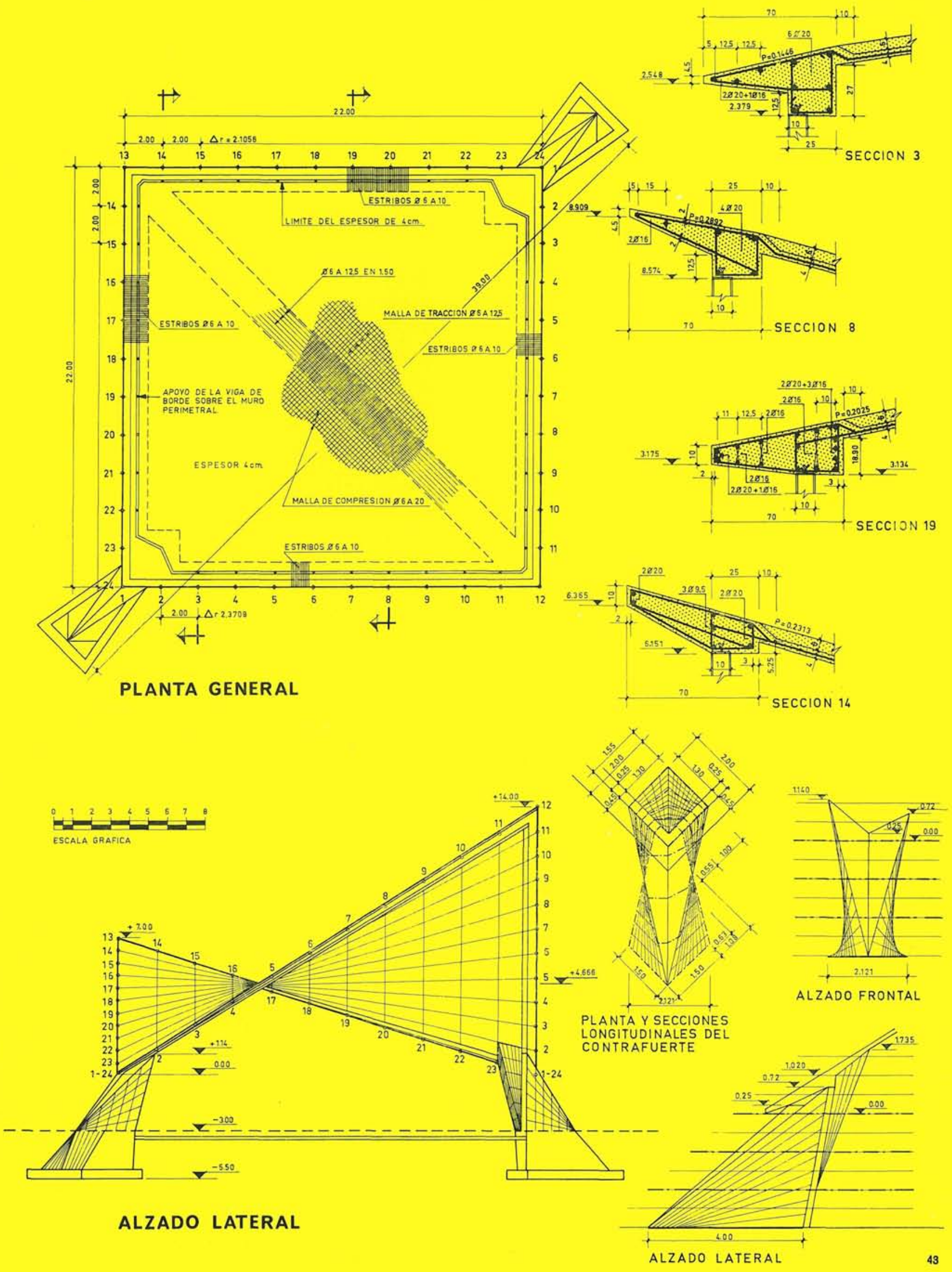


\section{iglesia y salón de actos en Torrelavega \\ (eubierta colgante sobre cadenas)}

PROPIETARIOS: Reverendos Padres de los Sagrados Corazones. ARQUITECTOS ESTRUCTURALES:

José Ruiz-Castillo.

Ricardo Urgoiti.

El conjunto de iglesia con salón de actos debajo tenía una forma en planta de corona circular; muy determinada por el emplazamiento del edificio, ligado a un conjunto arquitectónico muy denso.

La forma inicial fue decidida, desde un punto de vista volumétrico, proyectándose la contrucción de los muros laterales en hormigón, con la intención de dejar este material aparente por ambas caras, con inscripciones grabadas preparadas en el encofrado. Advertida la notable capacidad portante de la escuadra formada por los muros y el chaflán curvo en la parte del altar, el arquitecto tuvo la interesante idea de disponer una cubierta colgante, siendo él mismo quien sugirió el empleo de cadenas, si bien refiriéndose a cadenas de barco.

En seguida recogimos la idea con vistas a hacerla realizable, y caímos en la cuenta de que podría aprovecharse el tirón de la cubierta para comprimir las enormes vigas radiales que habrían de su. jetar el forjado.

Desembocamos en una solución realizada con éxito, según la cual toda la estructura del edificio trabaja de manera unitaria, en conjunto.

Las vigas radiales del forjado, con forma de $\mathrm{T}$ en el vano, embrochalan en una gran viga curva que coincide con la embocadura del salón de actos, la cual apoya a su vez en dos soportes metálicos laterales y en las paredes de hormigón. De esta manera pueden conseguirse momentos compensatorios negativos en los extremos del vano más largo. La prolongación de las vigas radiales en la parte del altar se encarga de aportar este momento negativo y de absorber la fuerte torsión de la referida viga curva; la cual pudo librarse de dicha solicitación y considerarse empotrada en sus extremos en virtud del doble apoyo lateral. El empuje transmitido por los contrafuertes bajos a las vigas radiales $T$ favorece la flexión de éstas y es soportado aún por toda la plataforma del altar, que actúa como una viga pared acostada, deliberadamente muy pesada, la cual a la vez acodala la escuadra que forman las paredes del fondo.

El tirón de la cubierta colgante en el anclaje alto es distribuido a las paredes laterales por medio de otra gran viga de $2,40 \mathrm{~m}$ de canto, cuvo peso propio se sostiene con jabalcones triangulares. Al diseñar la cimentación de los contrafuertes que soportan los anclajes bajos de la colgante, se había pensado, en un principio, aprovechar el empuje pasivo del terreno. Más adelante, por desconfianza a la deformación necesaria para poder contar con esta reacción, desde luego muy desfavorable para la viga radial, se prefirió intercalar unos soportes metálicos a modo de bielas, adelantando las zapatas de acuerdo con la inclinación de la resultante.
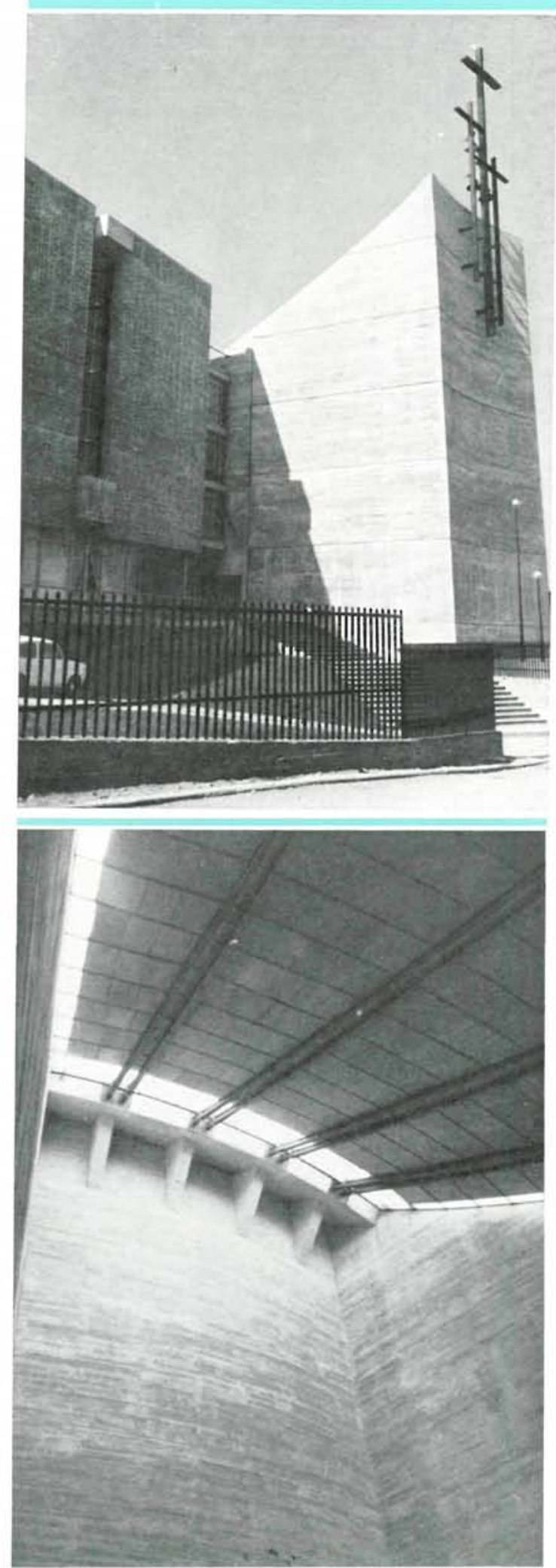


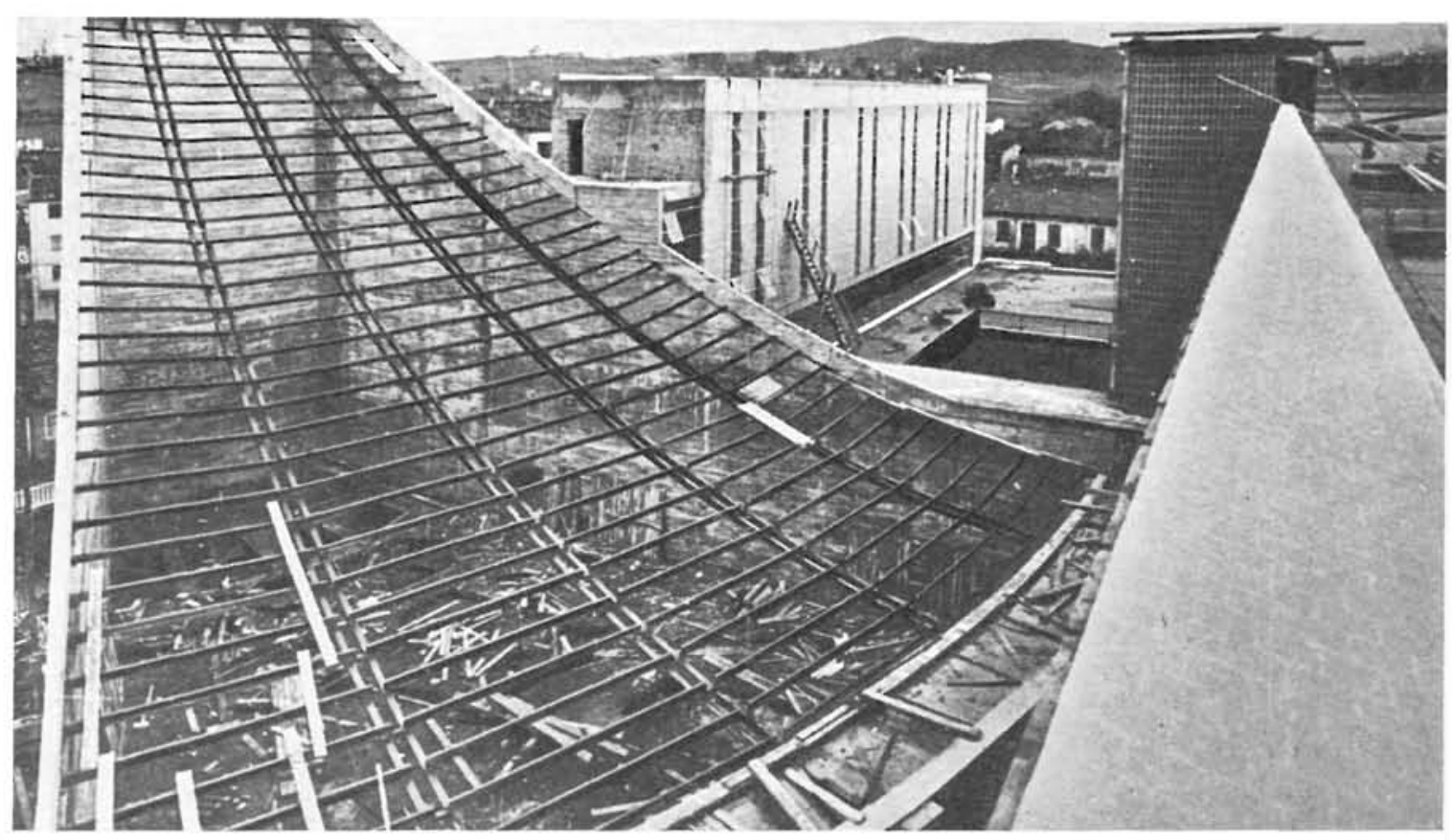

Correas montadas sobre cadenas.

La solución de cubierta colgante con las cadenas de barco era resistente, pero no proporcionaba suficiente estabilidad, ya que según la escasa curvatura en sentido de los meridianos de la superficie de revolución no podía asegurarse la inmovilidad de las cadenas por medio de vientos.

La estabilidad sólo podía conseguirse: $10^{\circ}$, aumentando considerablemente el peso propio en relación con la carga viva (succión del viento); $2 .^{\circ}$, dotando a la colgante de un cierto brazo de palanca, y soldando finalmente todas las uniones articuladas.

Pesos muertos colgados de las articulaciones entre eslabones para inmovilizar el techo antes del hormigonado.

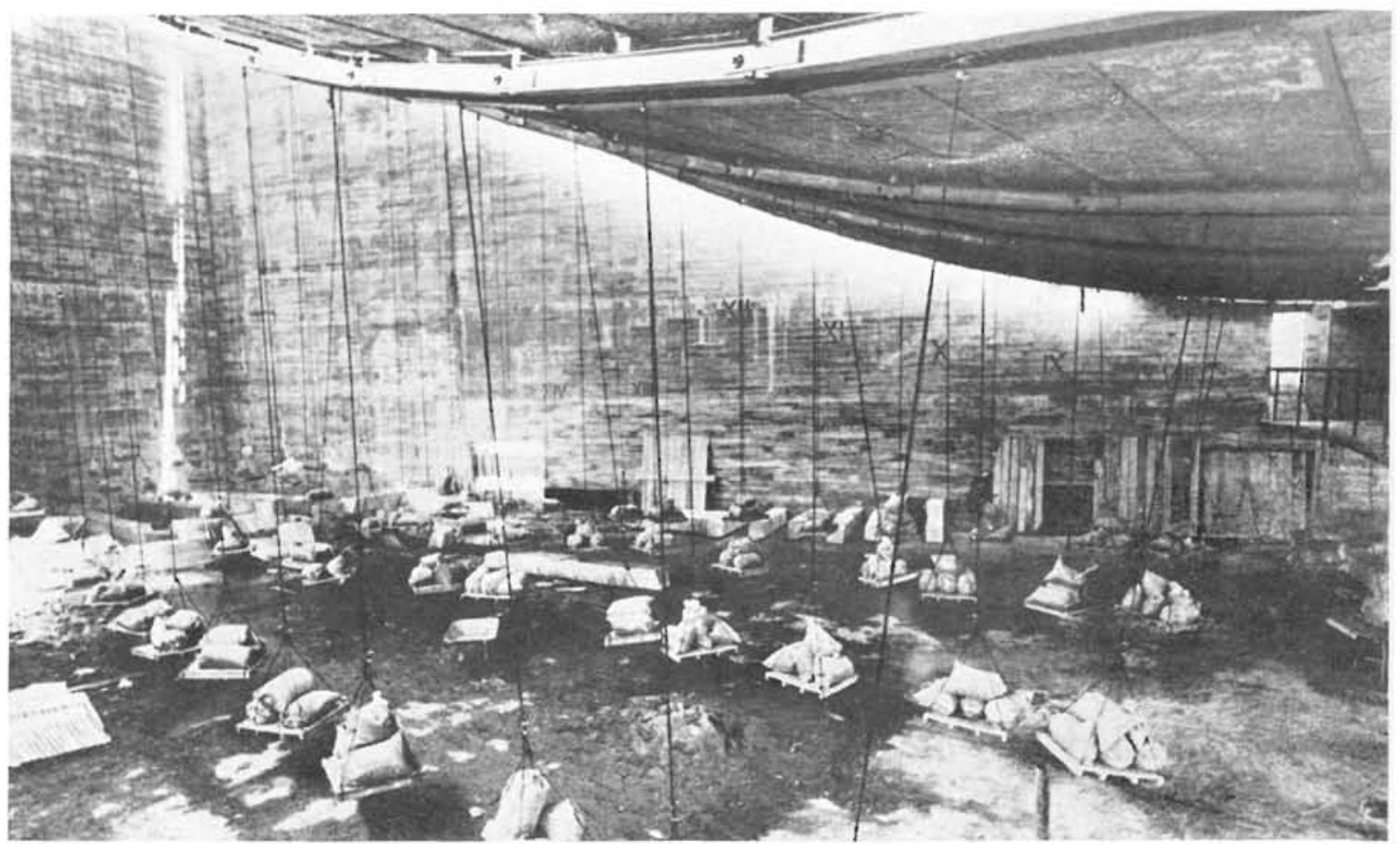



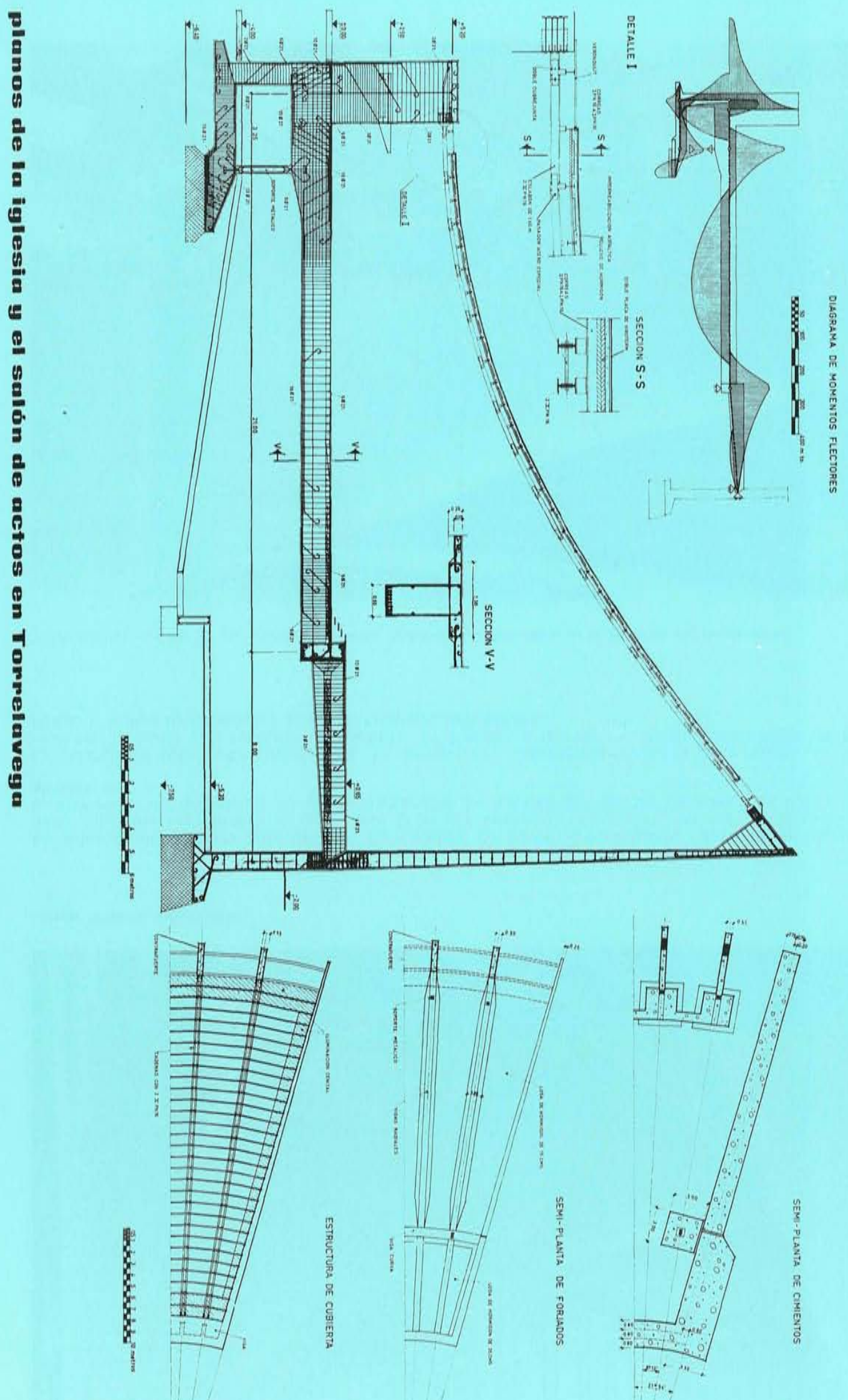
Para lograr que las cadenas trabajasen sin salirse de su plano proyectante, preferimos unirlas por parejas, escantillando con el mismo pasador de acero especial que formaba la articulación. Los eslabones de $1,90 \mathrm{~m}$ de longitud, se construyeron con 2 PN 16. A una cierta altura de éstos, salvada por unas piezas intermedias, se colocaron correas en el sentido de los meridianos, y acopladas a éstas unas placas de Viroterm a modo de encofrado perdido de una capa de hormigón de $4 \mathrm{~cm}$, armado con una ligera malla, rellenándose también los hombros junto a las alas de las correas, como si se tratase de un forjado.

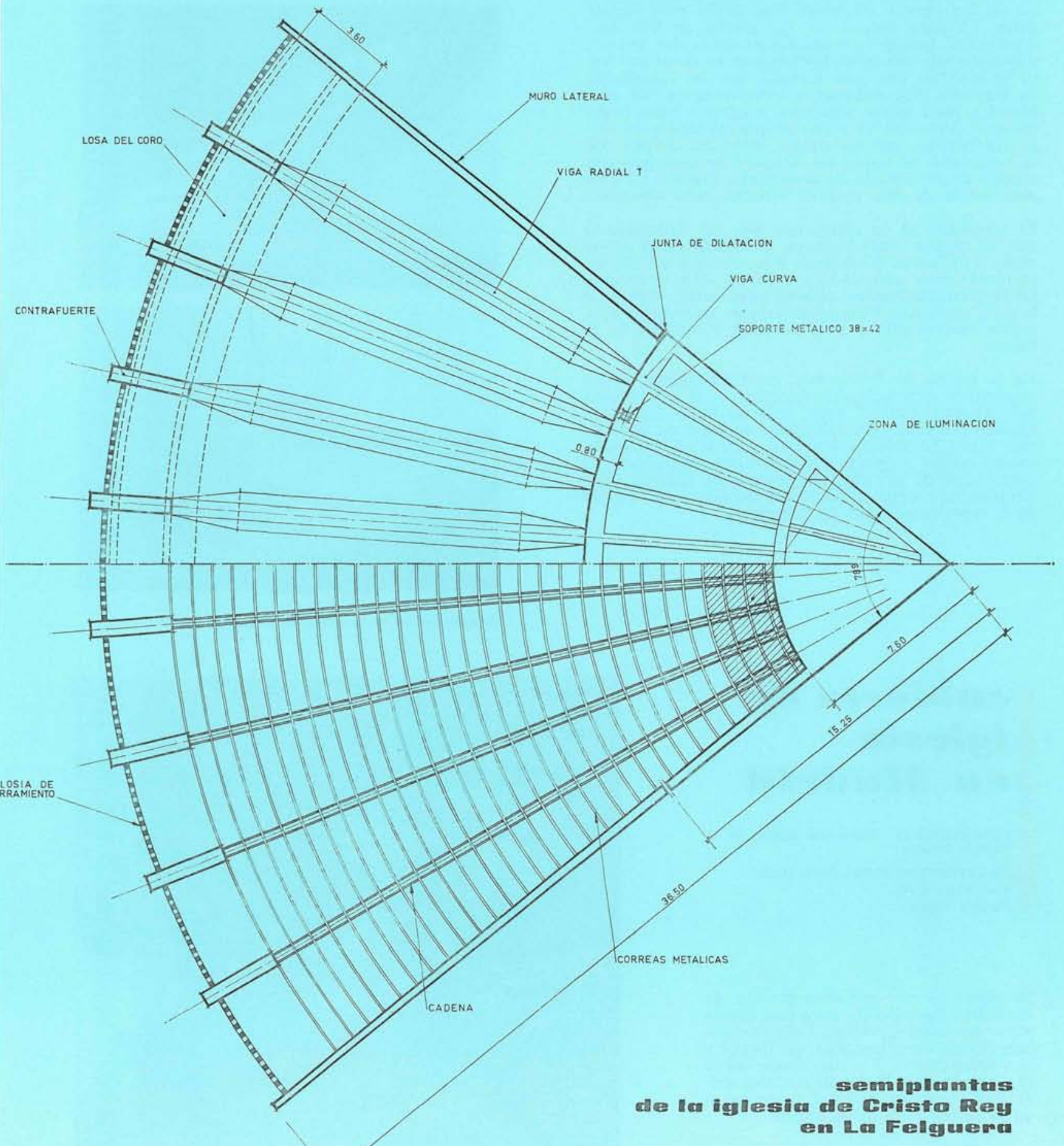

(sección y deralles semejanfes a la anferior) 
En efecto, el costo de la cubierta ha sido aproximadamente el de un forjado, ya que ha podido, además, construirse sin apenas medios auxiliares, por no ser necesario andamiaje alguno.

Las cadenas fueron enhebradas sobre el forjado, y colgadas de los anclajes por medio de diferenciales. Sobre ellas fácilmente se colocaron las correas. Existía un problema al no coincidir la forma definitiva del funicular de cargas trapezoidales con la forma inicial de la cadena, cuyo peso propio modificaba el diagrama de las cargas actuantes, haciéndolo más rectangular. El peso muerto de las placas de Viroterm colaboraba bastante aproximando estas dos curvas, y hubiera sido suficiente hormigonando, como en efecto se hizo, en una sola jornada, con un retardador de fraguado. Sin embargo, supervaloramos este problema y para mayor seguridad colgamos unos pesos muertos con sacos de arena proporcionales a las cargas definitivas, con los cuales, retirados después de la soldadura de todas las uniones, se consigue una especie de pretensado de la cubierta. Pudiera haberse prescindido de este trabajo, sencillo, pero laborioso.

El resultado de la estructura fue tan satisfactorio que se piensa reproducir en el futuro en diversos casos semejantes. El peso de hierro empleado por $\mathrm{m}^{2}$ en planta es de unos $24 \mathrm{~kg}$ y su elaboración elemental. La impermeabilización resulta muy barata debido a la gran pendiente. El aspecto interior, además, es altamente convincente por lo rotundo y sincero de la forma.

En la iglesia de Cristo Rey, en La Felguera, se ha construido otra cubierta semejante con una planta más abierta. Tras el altar, el tirón hacia dentro es tomado por una torre triangular en lugar de por una viga curva. La iluminación está concentrada al fondo, siendo quizás el efecto dinámico más dramático. El costo total de la cubierta colgante ha sido de unas $750 \mathrm{ptas} . / \mathrm{m}^{2}$, sorprendentemente económico a la vista de la espectacularidad de la solución.
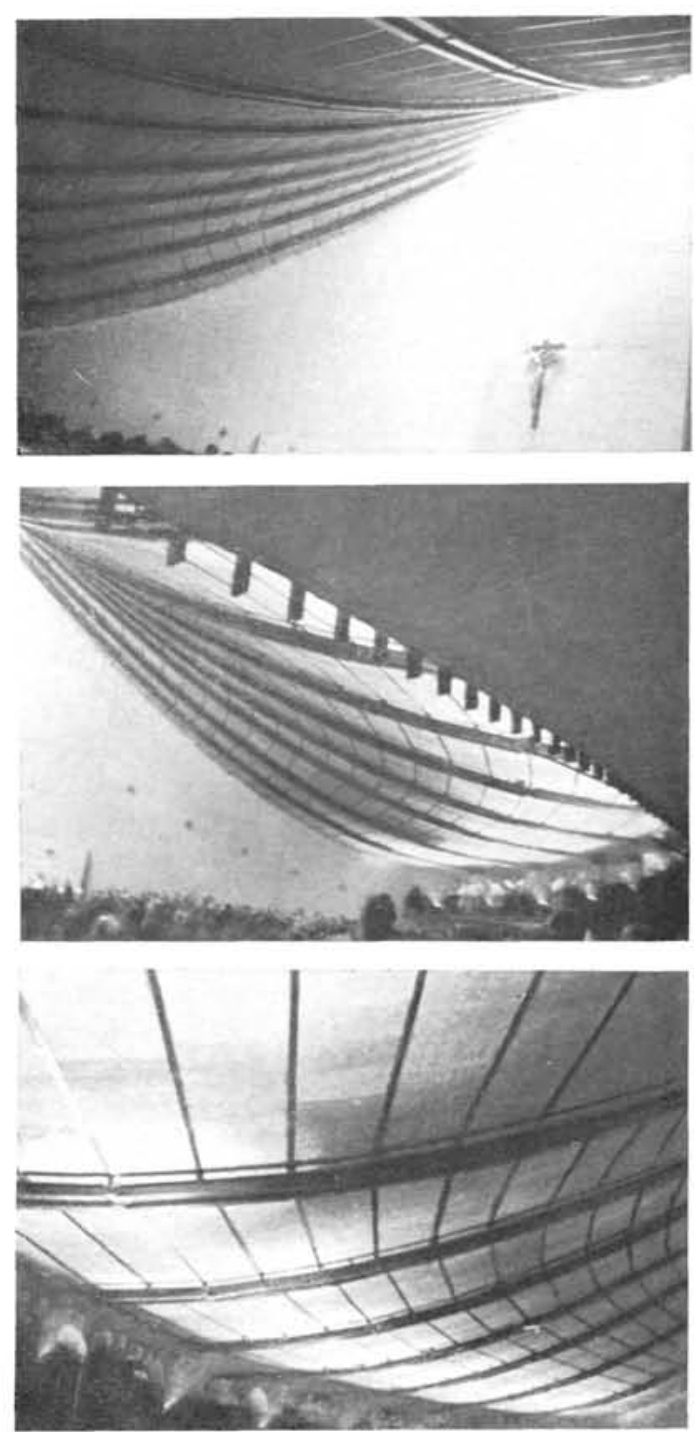

Aspecto interior de la iglesia de Cristo Rey.

\section{canbiemta de iglesia en Madrid}

PROPIETARIAS: Reverendas Madres de la Sagrada Familia.

ARQUITECTOS ESTRUCTURALES:

José Ruiz-Castillo.

Ricardo Urgoiti.

De nuevo se nos presentó el caso de construir una cubierta para una iglesia sobre un salón de actos. Esta vez con una planta muy irregular de forma y con arranques a $3 \mathrm{~m}$ de altura sobre el nivel de piso, lindando con una medianería, con un desnivel respecto al patio vecino de $9 \mathrm{~m}$ de altura.

Posición del trípode metálico del que se suspenden los tres paraboloides.

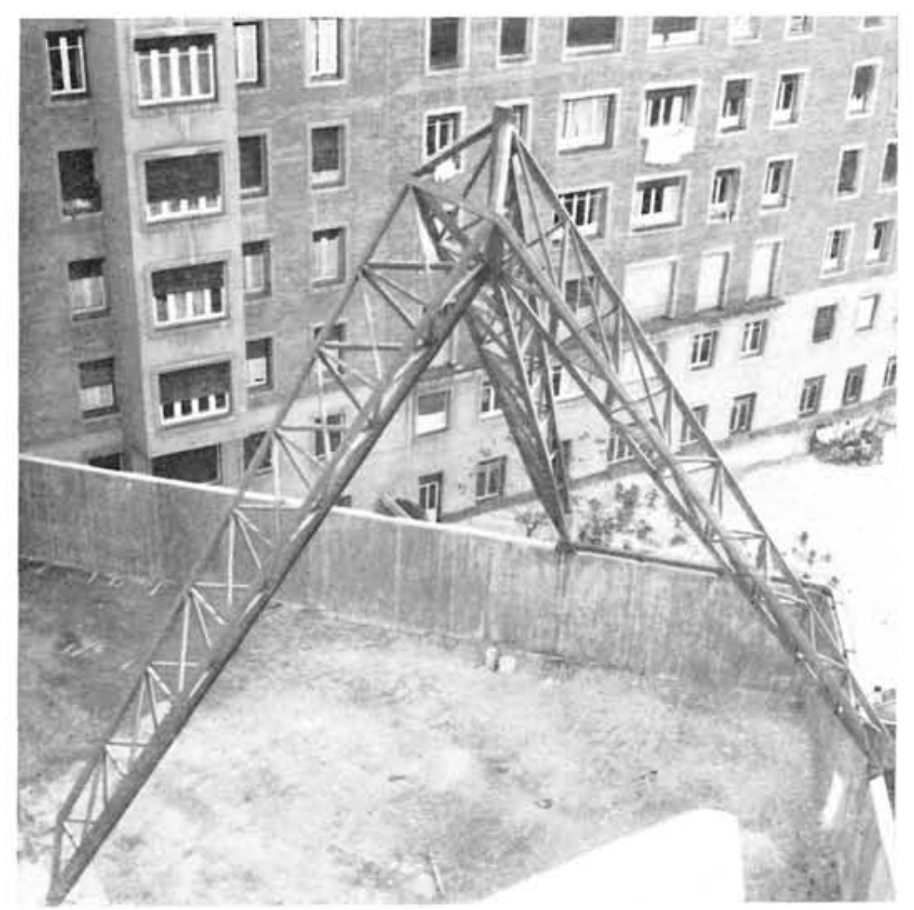



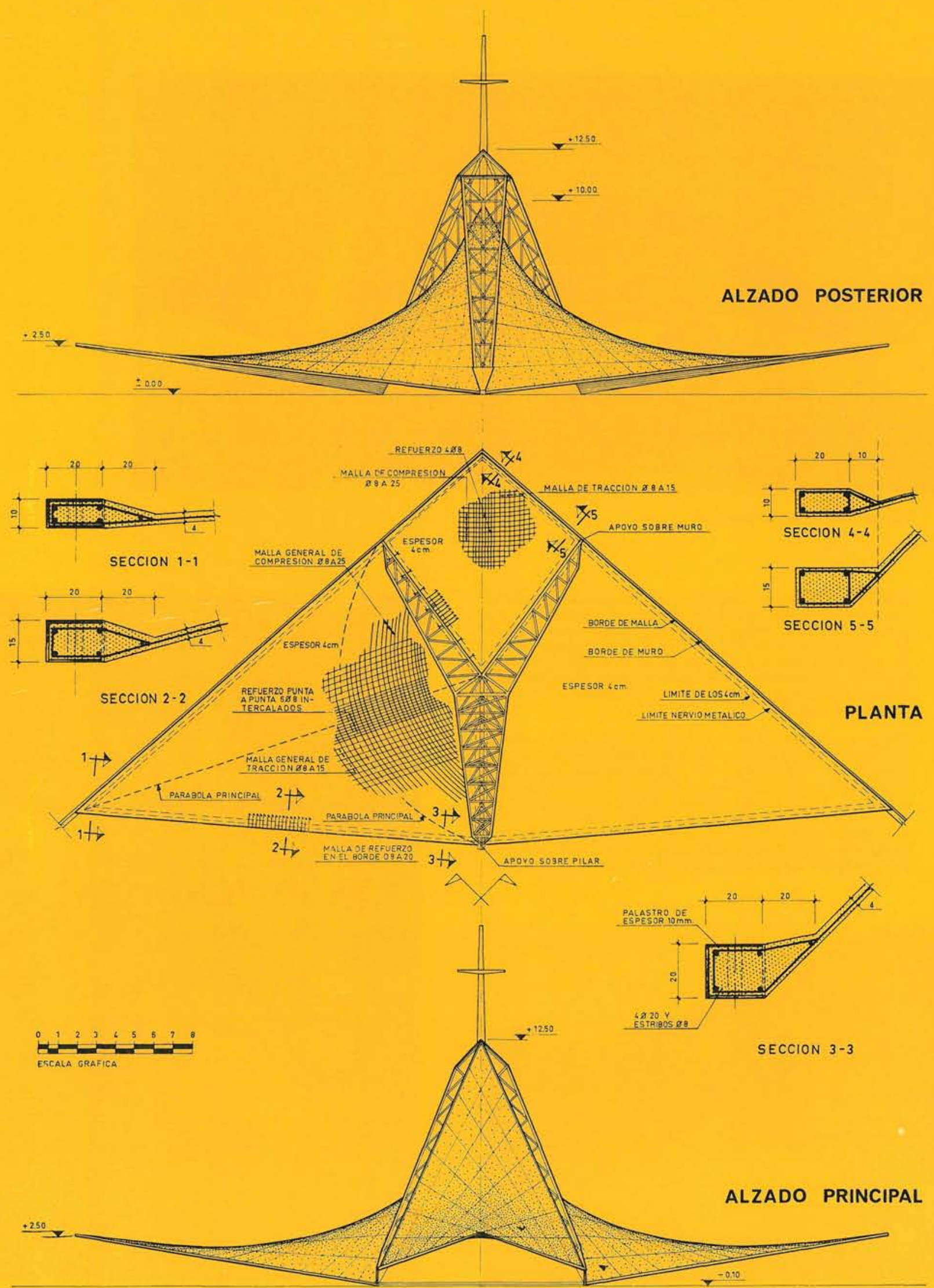


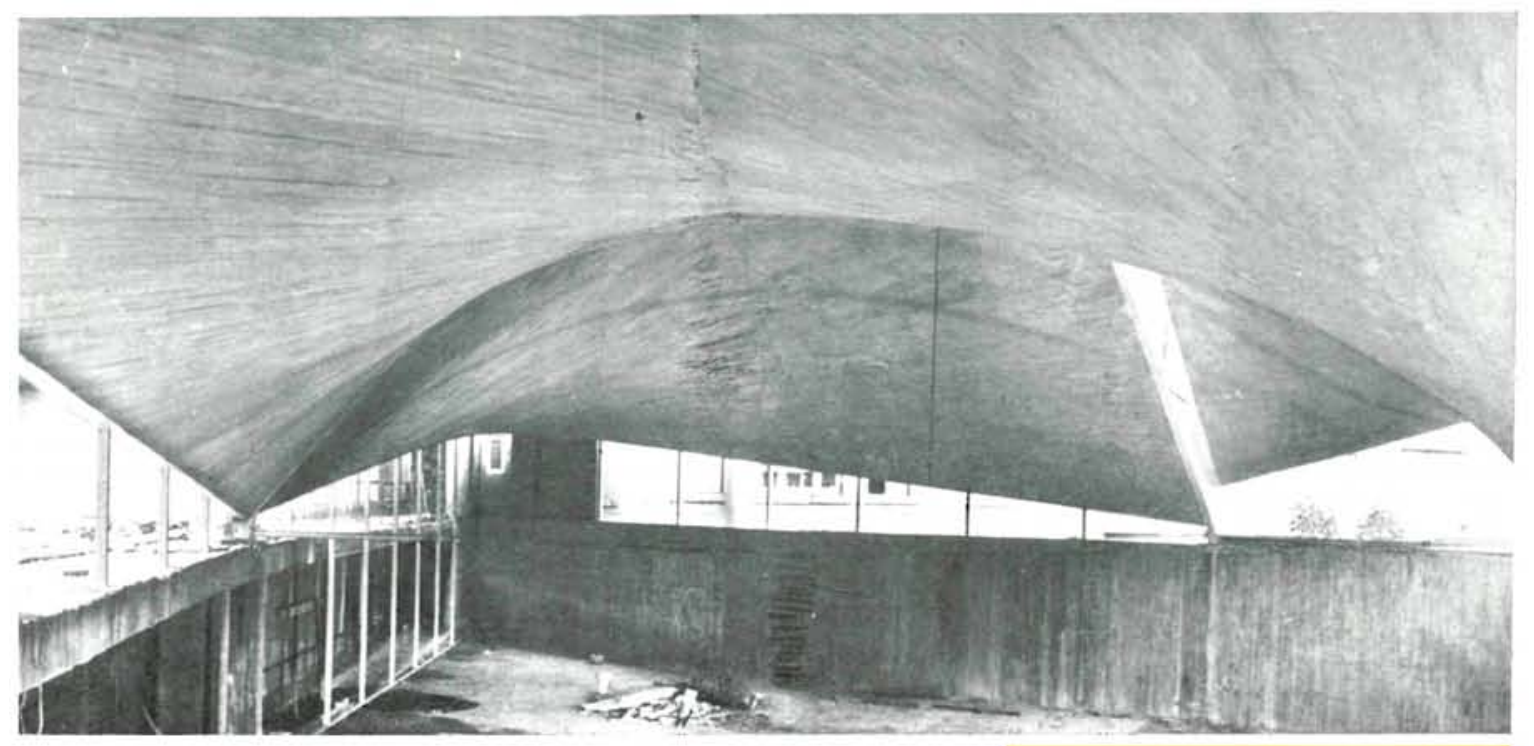

Vista del interior de la estructura.

Sobre la planta en cuestión, el arquitecto proyectó una cubierta muy difícil de realizar con tres hojas de paraboloide hiperbólico distintas, quizás inspirado en la famosa iglesia de Candela de San Vicente de Paúl. El problema era que mientras en ésta los tres paraboloides son iguales, en la estructura en cuestión eran iguales dos y otro distinto, pues la planta sólo posee un eje de simetría.

Obligados moralmente en nuestro deseo de «hacer méritos», adaptándonos religiosamente a la firme propuesta del arquitecto, nos comprometimos a hacer realizable la idea. Hubimos de idear un trípode metálico de $12,50 \mathrm{~m}$ de altura, apoyado en muros de $20 \mathrm{~cm}$ de espesor, capaz de resistir esfuerzos fuera del plano proyectante en dos de sus patas. Dichas patas son triangulares reticulares, de tamaño variable partiendo de cero en el apoyo. La tercera pata podría
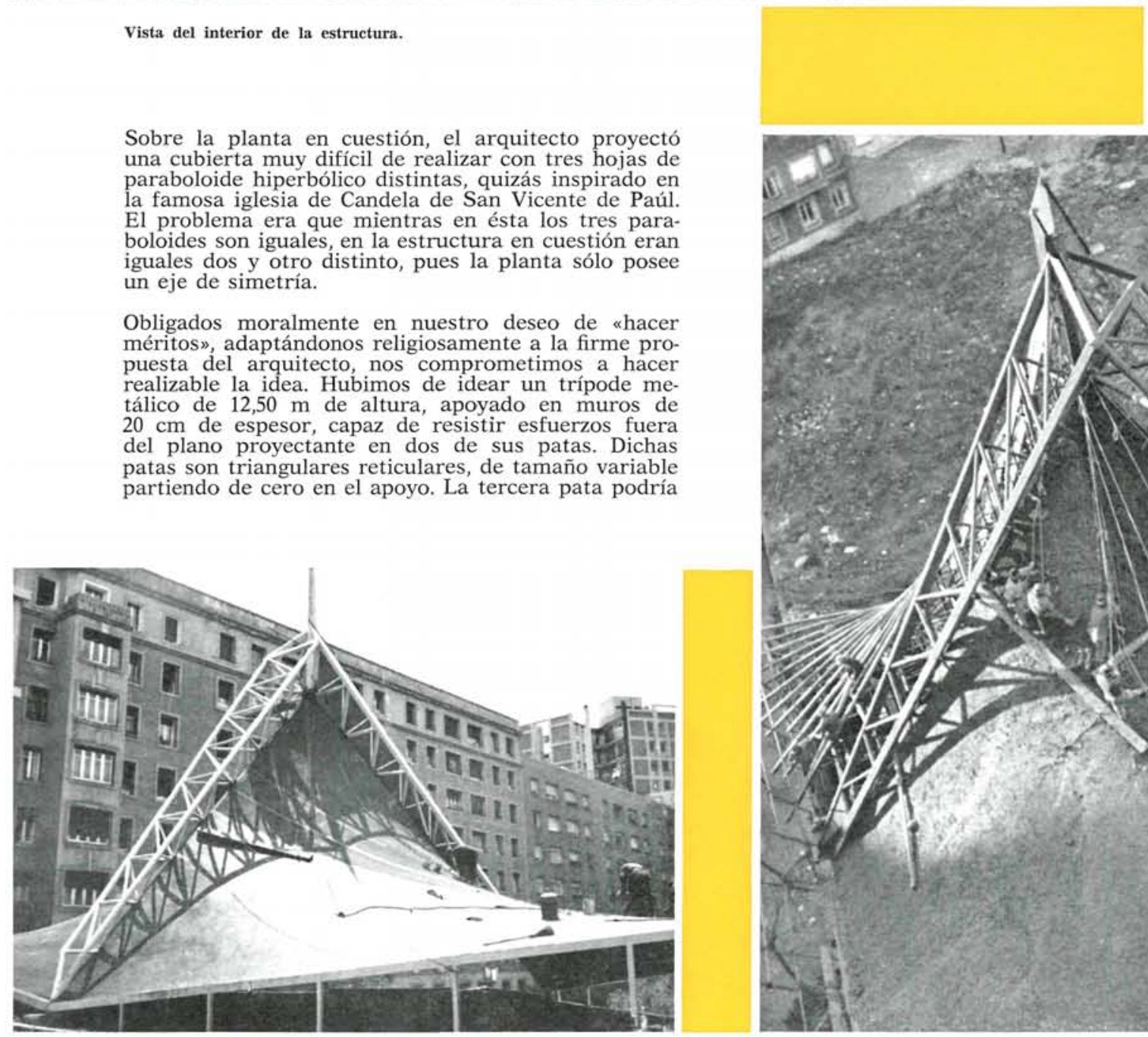

Aspecto exterior.

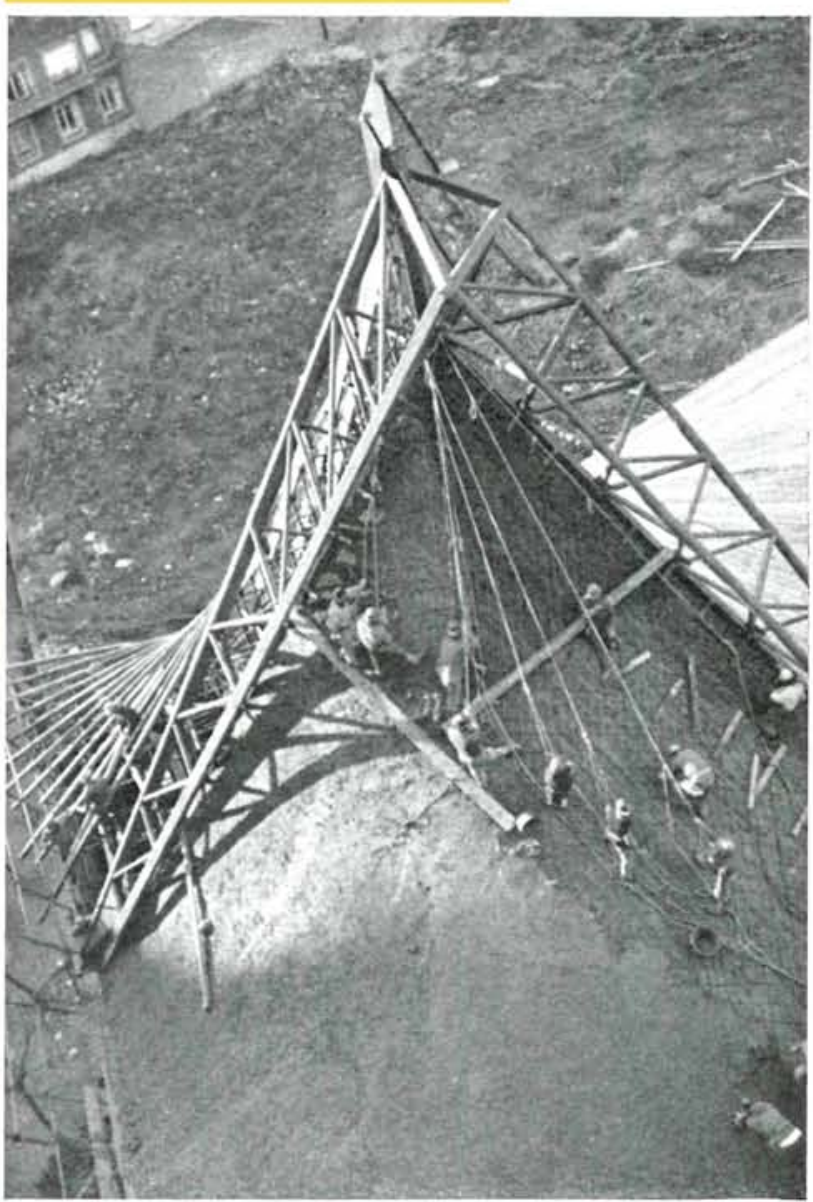

Hormigonado de la cubierta. 
haber sido plana, pero preferimos hacerla también triangular, de modo que las tres patas nacen de un tetraedro a $2,50 \mathrm{~m}$ de altura. En las patas más próximas al altar una de las caras queda en un plano vertical, donde se coloca un ventanal para iluminarlo de frente.

Las tres hojas de paraboloide cuelgan materialmente del trípode, produciendo esfuerzos muy desiguales. El cálculo se realizó en programador electrónico, resolviendo un cremona espacial muy complicado. Al unificar, por facilidad de ejecución, las secciones de muchas barras, la estructura metálica quedó algo des proporcionada en su aspecto exterior por su envergadura. Sin embargo, de acuerdo con la Dirección Facultativa de la obra, debido a la poco brillante situación de la iglesia en un patio de manzana, lo importante era el aspecto interior, el cual, sin duda, resulta muy dinámico e interesante.

La ejecución de la obra fue también harto compleja, sobre todo el izado del trípode, que tuvo que hacerse sin grúa. El hormigonado también fue difícil, ejecutado en una pendiente de $75^{\circ}$. Una vez terminada la construcción, cabría preguntarse si en realidad compensa el plegarse hasta tal punto a la idea arquitectónica, aun desorbitando la cuestión estructural, pudiendo haber elegido otras soluciones más elementales.

El costo de la obra, que es, sin duda, un factor decisivo en esta apreciación, parece abogar en favor de la solución realizada, ya que toda la cubierta, incluso control técnico, cálculo, aislamiento e impermeabilización, con buenos acabados, costó dos millones y medio de pesetas, que es poco más de lo que hubiera costado una cubierta metálica corriente. Lo cual demuestra la relativa economía de las estructuras laminares debido al reducidísimo empleo de material, a pesar de sus dificultades técnicas y constructivas.

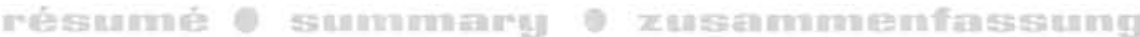

\section{Voiles mimces en Espragne}

Il s'agit ici de trois voiles minces pour des églises situées en différents points d'Espagne.

Cet article fait ressortir leur comportement et les magnifiques résultats obtenus, ainsi que leur coût relativement bas, surtout à la vue de la plasticité des formes et du caractère hautement spectaculaire des solutions adoptées.

L'architecte Fray Coello de Portugal a apporté les idées générales de conception. L'entreprise «Construcciones La. minares» s'est chargée de la supervision et du calcul, des plans, et même de la construction en certains cas.

Ce travail a été présenté à l'IASS, 1967, au Mexique.

\section{Thin shell structures in Sperim}

This article deals with three interesting thin shell structures that serve as roofs for churches in various parts of Spain.

The excellent functional properties of these shells is worth noting as well as their spectacular aspect and relatively low cost, especially if their complex geometry and striking structural effectiveness are taken into account.

The Portuguese architect Fray Coello provided the general pattern of the designs, and the firm Construcciones La. minares, S. L., was responsible for the supervision of the construction, the calculations, plans, details and the actual construction.

This paper was submited to IASS, 1967, in Mexico.

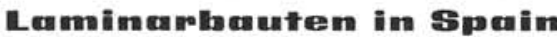

Hier werden die interessanten Laminardecken dreier Kirchen in verschiedenen Gegenden Spaniens vorgestellt.

Die Ergebnisse sind äusserst beeindruckend. Man hat eine grosse Wirking unter relativ geringem Kostenaufwand erreicht. Besondere Beachtung verdienen die plastischen Bauformen und die aufsehenerregende Gestaltung.

Architekt Fray Coello aus Portugal lieferte die grundlegenden Ideen für den Entwurf; für Aufsicht, Berechnung, Pläne und teilweise auch den Bau war die Firma Construcciones Laminares, S. L., verantwortlich.

Die Arbeiten wurden auf der IASS, 1967, in Mexico ausgestellt. 